\title{
Dutch dyslexic adolescents: phonological-core variable-orthographic differences
}

\author{
Judith Bekebrede $\cdot$ Aryan van der Leij • \\ David L. Share
}

Published online: 12 December 2007

(C) The Author(s) 2007

\begin{abstract}
The phonological-core variable-orthographic differences (PCVOD) model [van der Leij, \& Morfidi (2006). Journal of Learning Disabilities, 39, 74-90] has been proposed as an explanation for the heterogeneity among dyslexic readers in their profiles of reading-related subskills. The predictions of this model were investigated in a sample of 72 Dutch secondary school students (dyslexics and controls). First, the PCVOD assumption was confirmed that phonological processing and orthographic competence are independent contributors to the prediction of reading fluency and spelling. Among the phonological processing tasks, phonological recoding explained substantial unique variance, but not phonemic awareness or rapid serial naming. Next, the dyslexic readers were divided into two subgroups based on high $\left(\mathrm{ORTH}^{+}\right)$and low levels $\left(\mathrm{ORTH}^{-}\right)$of orthographic competence. Both subgroups performed below controls on all measures tapping phonological processing, reading and spelling but the $\mathrm{ORTH}^{+}$group performed as well as nondisabled controls on Dutch and English orthographic choice. As predicted by the model, there were no differences between the subgroups on the tasks that depend on phonological processing, with or without reading. There were differences on Dutch word reading fluency and spelling. Furthermore, the $\mathrm{ORTH}^{+}$subgroup outperformed $\mathrm{ORTH}^{-}$on tasks demanding speeded word processing such as 'flashed' presentation. This finding was independent of lexicality (words or pseudowords), language (Dutch or English) or response mode (lexical decision or typing), but restricted to silent reading. This supports the view that the $\mathrm{ORTH}^{+}$subgroup is better at identifying larger orthographic units. There was no indication of differences between the subgroups in reading experience. Our data, therefore, support the PCVOD model.
\end{abstract}

J. Bekebrede $(\bowtie) \cdot$ A. van der Leij

Department of Education, University of Amsterdam, PO Box 94208, Amsterdam 1090 GE,

The Netherlands

e-mail: J.I.Bekebrede@uva.nl

D. L. Share

Department of Learning Disabilities, University of Haifa, Haifa 31905, Israel 
Keywords Dyslexia - Orthography $\cdot$ Phonology $\cdot$ Second language ·

Subtypes

\section{Introduction}

Over the last few decades there has been a great deal of research investigating the causes of developmental dyslexia (see for recent reviews, Beaton, 2004; Vellutino, Fletcher, Snowling, \& Scanlon, 2004). Because reading acquisition is a complex process generating large individual differences (Share \& Stanovich, 1995), the population of dyslexic children is not homogenous with respect to all reading-related subskills. Whereas there is consensus among researchers that the core problem in dyslexia lays in phonological processing deficits (Bailey, Manis, Pedersen, \& Seidenberg, 2004; Vellutino et al., 2004), there is no consensus as regards the heterogeneity in subskills that are less reliant on phonological processing (Castles \& Coltheart, 1993; Wolf \& Bowers, 1999; Bailey et al., 2004; Bosse, Tainturier, \& Valdois, 2007). The present study investigates one of these possible sources of the heterogeneity in cognitive functioning of dyslexics: orthographic competence.

First, it will be argued that phonological processing is a universal subskill of reading an alphabetic language, independent of orthographic complexity. Evidence supporting the phonological deficit as a theory of dyslexia will be briefly reviewed. We then outline arguments supporting the claim that orthographic competence is an independent predictor of reading development and, furthermore, may be the source of variable differences within the group of dyslexics.

\section{Universality of phonological processing}

It is well established that phonological processing is crucial in learning to read. Although the term phonological processing is normally used to refer to a variety of tasks tapping perception, learning, and memory for speech-based (phonological) information (see e.g., Shankweiler \& Fowler, 2004; Share, 1995; Wagner \& Torgesen, 1987), phonemic awareness represents the most comprehensively investigated constituent of the phonological processing constellation. Phonemic awareness, the understanding that a spoken word consists of a sequence of sounds and the ability to manipulate those sounds, has been shown to be one of the most potent predictors of early reading (Bowey, 2005; Ehri, Nunes, Stahl, \& Willows, 2001). Underlining the universality of phonemic awareness, cross-linguistic transfer has been found in bilingual studies with Spanish and English speaking children (Durgunoğlu, Nagy, \& Hancin-Bhatt, 1993; Lindsey, Manis, \& Bailey, 2003), in French/English speaking children (Comeau, Cormier, Grandmaison, \& Lacroix, 1999), Hebrew/English (Geva \& Siegel, 2000) and Russian/Hebrew children (Schwartz, Leikin, \& Share, 2005). There is cross-linguistic transfer even in children who do not learn an alphabetic orthography. Gottardo, Yan, Siegel, and Wade-Woolley (2001) found that Chinese rhyme detection skills predict English reading skills in Chinese children learning English as a second language. 
Another phonological processing variable, rapid serial naming, involves the quick retrieval of symbolic information from long-term memory (Jorm \& Share, 1983; Wagner \& Torgesen, 1987). Rapid serial naming, especially of digits and letters, plays a significant role in predicting reading. Cardoso-Martins and Pennington (2004) found that rapid naming of letters and digits in kindergarten predicted fluent reading and spelling in English, but was a weaker predictor of word and pseudoword reading accuracy. Phonemic awareness was found to be a more robust predictor, whereas rapid serial naming played only a modest role. However, in a study of young Dutch adolescents learning English as a second language, rapid serial naming was the strongest predictor of reading in both languages (Morfidi, van der Leij, de Jong, Scheltinga, \& Bekebrede, 2007). It appears that in languages with more consistent one-to-one grapheme-phoneme mappings, rapid serial naming is a strong predictor of reading fluency at every age, whereas phonemic awareness only plays a major role in predicting reading among beginning readers. Once children have mastered the spelling-sound code (after grade one in transparent orthographies) it is harder to detect the independent contribution of phonemic awareness to reading performance because individual differences in a relatively consistent orthography mainly concern speed of reading and not accuracy (e.g., German: Wimmer, Mayringer, \& Landerl, 2000; Dutch: de Jong \& van der Leij, 1999). However, as is argued by Caravolas, Volín, and Hulme (2005), psychometric qualities of the phonemic awareness measures may be decisive in explaining the contrasting results (see also Morfidi et al., 2007).

Phonological processing is also implicated in phonological recoding, given that phonological recoding is the ability to use grapheme-phoneme translation and phoneme blending strategies to identify unfamiliar words. As a consequence, it implies phonemic awareness and letter knowledge. Because many words are unfamiliar to the young reader at the sight-word level, they can be expected to be read by phonological recoding, using the grapheme-phoneme correspondence rules. However, the more experienced reader may also use phonological recoding when he has to read a word that he has not seen before. To ensure unfamiliarity and trigger phonological recoding, tasks with pseudowords have been used frequently in research. Phonological recoding is the key mechanism in reading acquisition. According to Share (1995), phonological recoding forms the basis for direct word recognition because repeated (successful) recoding of unfamiliar words acts as a self-teaching mechanism enabling the acquisition of word-specific orthographic knowledge. This process of self-teaching mechanism appears to be a universal means of bootstrapping the process of orthographic learning not only in pointed Hebrew, which is a very shallow orthography (Share, 1999, 2004), but also in moderately shallow Dutch (de Jong \& Share, 2007) and in English-the deepest of alphabetic orthographies (Bowey \& Miller, 2007; Bowey \& Muller, 2005; Cunningham, 2006; Kyte \& Johnson, 2006; Nation, Angell, \& Castles, 2007).

Orthographic competence as an additional independent predictor

Phonological processing is not the only predictor of reading development. Orthographic competence, often measured by lexical decision tasks, contributes 
unique variance to word recognition even after controlling for phonological processing (i.e., phonological recoding and phonemic awareness) (Cunningham, Perry, \& Stanovich, 2001). In addition, orthographic competence contributes unique variance after controlling for print exposure, in children as well as in adults (Cunningham, Perry, Stanovich, \& Share, 2002; Cunningham \& Stanovich, 1990; Stanovich \& West, 1989). The contribution of orthographic competence has also been found to increase with age (Badian, 2001). Although orthographic competence as a contributor to reading development has received less attention than phonological processing in a cross-linguistic perspective, there are indications that it is an independent predictor in other languages and orthographies than English (e.g., in Chinese: Ho, Chan, Lee, Tsang, \& Luan, 2004; Dutch: Morfidi et al., 2007).

It should be noted that there has been considerable debate about the role of orthographic processing skill with regard to word identification in reading and orthographic learning (see for reviews Burt, 2006; Castles \& Nation, 2006). Two main concerns have been voiced. One is that most studies do not involve measures of on-line orthographic processing as distinct from phonological recoding which is, by definition, process-oriented. Most tasks measure the outcome of the learning process, i.e., word-specific knowledge (lexical decision). As a consequence, most, if not all, studies do not contribute to the understanding of orthographic processing skill as a distinct component of word identification and reading acquisition. The second concern is that, to assess the contribution of orthographic processing skill to differences in reading development, the influence of factors such as phonological processing, reading experience and verbal competence should be taken into account first. Because the present study has relatively experienced readers as participantson average, 15.5 years of age - it was not designed as a study of early orthographic learning and on-line orthographic processing, and cannot shed light on the first issue. By controlling the factors mentioned in the second issue (comparable to the studies of Cunningham et al., 2001, 2002), our study aimed to contribute to the understanding of individual differences, in particular the use of orthographic knowledge. It therefore extends the existing literature in two ways. First, individual differences are studied in students who have learned to read and spell in their native Dutch, which has a relatively shallow orthography, and learn English as a second language. This is important because findings from English-language investigations should be verified in more transparent orthographies. Second, both reading and spelling are taken as variables to be predicted. To underscore the fact that orthographic processing is not measured in a direct way, the term orthographic competence will be used throughout this paper.

\section{Universality of the phonological deficit}

Cross-linguistically, it is well established that dyslexia is strongly related to deficits in phonological processing. There has been some debate about the specific role of phonemic awareness in relative consistent orthographies (see for example Landerl \& Wimmer, 2000; Caravolas et al., 2005). However, as is argued by de Jong and van der Leij (2003), it may be assumed that although the correlation between 
phonemic awareness and reading performance tends to decrease during primary school when the native language has a relatively shallow orthography, phonemic processing of dyslexic readers is still deficient at a later age, provided that the measures are sufficiently sensitive. With respect to rapid serial naming, there is strong evidence across languages that dyslexics are uniformly slower than controls (e.g., de Jong \& van der Leij, 2003; Denckla \& Rudel, 1974; Gallagher, Laxon, Armstrong, \& Frith, 1996; Ho \& Lai, 1999; Wimmer et al., 2000; Wolf, Bally, \& Morris, 1986). Furthermore, a major characteristic of dyslexics is that they have problems in phonological recoding irrespective of the transparency of the orthography. The well-known finding that dyslexics have poor phonological recoding skills in English (Rack, Snowling, \& Olson, 1992) can be generalized to languages with a more transparent orthography (e.g., Swedish: Miller-Guron \& Lundberg, 2000; German: Landerl \& Wimmer, 2000; Dutch: van der Leij \& van Daal, 1999) as well as in cross-linguistic studies (e.g., van der Leij \& Morfidi, 2006). One of the most powerful paradigms for revealing the defective phonological recoding mechanism of dyslexics is by brief presentation of the stimulus word. Yap and van der Leij (1993) were able to demonstrate that when dyslexics are required to read briefly presented words and pseudowords ("flashed" for $200 \mathrm{~ms}$ ), they were more profoundly impaired on pseudowords compared to words, a result that the authors have interpreted as evidence of an 'automatic decoding deficit.'

\section{Variability in orthographic competence}

Although most studies find differences in orthographic competence between groups of normal achieving students and dyslexics, there is evidence suggesting larger variability in orthographic competence within the group of dyslexics than in phonological processing, in particular, phonological recoding. The larger variability has been investigated in two studies. In a study with Swedish college students, Miller-Guron and Lundberg (2000) found a subgroup of dyslexic readers who read better in English than in their native Swedish, although Swedish has a transparent orthography. In contrast, another subgroup did not perform better in English than in Swedish. In a transparent script, words can be read using a grapheme-phoneme decoding strategy, whereas in English the abundant irregularity of graphemephoneme correspondences is likely to deter readers from using a similar strategy (Seymour, Aro, \& Erskine, 2003; Ziegler \& Goswami, 2005). Instead, it may be assumed that the greater orthographic irregularity of English is more favorable to a sight-word or a larger orthographic unit approach (e.g., orthographic neighbors) than to a grapheme-phoneme decoding strategy, in contrast to Swedish, where decoding would be favored. Apparently, some of the dyslexics in the study of Miller-Guron and Lundberg (2000) had the ability to use such orthographic skills in English whereas others did not.

In a similar study, van der Leij and Morfidi (2006) investigated Dutch dyslexic adolescents who began to learn English in secondary school. They also found a subgroup of dyslexic students who performed better in English than was expected based on their Dutch reading skills. This subgroup had superior orthographic 
knowledge in both Dutch and English compared to another subgroup of dyslexics who were comparable in phonological processing and Dutch reading but performed more poorly in orthographic knowledge in both languages and in English word reading.

The findings that within the group of dyslexics the phonological core deficit may be accompanied by variability in a processing domain that is less dependent on phonological processing may be conceptualized within the framework that Stanovich proposed for all poor readers-both dyslexic and non-dyslexic (Stanovich, 1988; see also Stanovich \& Siegel, 1994). His phonological-core variabledifference model states there is a core phonological deficit in children with dyslexia. Independent of this core deficit the performance in task related skills might vary considerably, most notably in general intelligence. Thus dyslexics, with performance in general intelligence in the normal range, share the same phonological deficit with poor readers who have subnormal intelligence, the garden-variety poor readers. The latter group, however, is characterized by additional non-phonological deficits that vary depending on IQ. In the same vain but restricted to the dyslexic group and the reading domain, van der Leij and Morfidi (2006) developed their phonological-core variable-orthographic differences model (PCVOD). The authors suggested that the differences between the two dyslexic subgroups in English could well be explained by the variable way the dyslexics performed in orthographic competence. The students with better orthographic competence may have favored reading strategies other than grapheme-phoneme decoding, and showed a 'large orthographic unit preference' (van der Leij \& van Daal, 1999; see also Miller-Guron \& Lundberg, 2000; Ziegler \& Goswami, 2005). Because the subgroups were comparable in defective phonological processing in both languages, the findings support a model that postulates a universal phonological deficit in all dyslexics and a variable difference in orthographic competence. The PCVOD model is the focus of the present study.

\section{Orthographic competence in spelling}

Thus far, orthographic competence has only been discussed with regard to reading. In reading, orthographic knowledge is the basis for recognizing words or large sublexical parts of words. In spelling, this same knowledge is important in a somewhat different way. The mapping of phonology to orthography, which is used for spelling however, is more variable than from orthography to phonology as required in reading (Fletcher-Flinn, Shankweiler, \& Frost, 2004), thus making spelling more difficult to acquire than reading. Even in most transparent orthographies, there are discrepancies in regularity for reading and spelling (see Joshi \& Aaron, 2005). Regularity usually refers to the grapheme-to-phoneme correspondences relevant to reading (so-called "forward" regularity), but there often are more irregularities in the phoneme-to-grapheme correspondences relevant to spelling ("backward" regularity). Because of these irregularities in phoneme-tographeme correspondences there are often more ways to spell a pronounced word, than to read/pronounce a written word, even in relatively transparent orthographies 
such as Dutch and German (Bosman \& van Orden, 1997; Wimmer \& Mayringer, 2002). For example, the words sleep and cheap are both pronounced with the same vowel, but are spelled differently. Even knowing how to read these two words, a child required to spell a new unseen word containing the same vowel (e.g., leap), has no way of choosing between the two ways of spelling the vowel. Moreover, spelling is more difficult because it relies completely on representations in memory, than reading that relies on identification and recognition processes (Fletcher-Flinn et al., 2004). It may be assumed that orthographic knowledge at all phonological levels-corresponding with single phonemes, speech sound clusters, whole wordsis a critical element in spelling (Ziegler, Stone, \& Jacobs, 1997). There is evidence that dyslexic readers have less orthographic knowledge than age controls at sixth grade as indicated by their poorer spelling performance (e.g., de Jong \& van der Leij, 2003). Because spelling relies heavily on orthographic competence, the PCVOD model, if supported with regard to reading, also predicts substantial variability in spelling within the group of dyslexics.

\section{Research questions}

The preceding discussion suggests that both phonology and orthography are important in reading and spelling. Over and above phonological processing, therefore, orthographic competence might be a fruitful avenue for understanding the heterogeneity among dyslexics.

The first purpose of our study was to test the 'phonological-core variableorthographic differences' (PCVOD) model within the context of a study designed to replicate and extend the work of van der Leij and Morfidi (2006). This model postulates a core phonological deficit common to all dyslexics, with co-existing differences in orthographic competence.

Therefore our study made three major predictions:

(a) Phonological processing and orthographic competence contribute independently to the explanation of variance in reading and spelling,

(b) all dyslexics suffer from a phonological core deficit,

(c) within the group of dyslexics there exists larger variability in orthographic competence, than in phonological processing. Some dyslexics demonstrate relatively "normal" orthographic competence and outperform dyslexics with poorer orthographic competence in tasks that rely on orthographic competence.

\section{Study design}

Following Cunningham et al. (2001, p. 564), our first aim was to confirm that individual differences in orthographic competence are not parasitic on phonological processing. Thus, orthographic competence should contribute to the prediction of word reading fluency after the variance accounted for by vocabulary and 
phonological processing had been partialed out. Accordingly, composites were constructed for phonological processing and orthographic competence. To control for phonological processing, phonological recoding (grapheme-phoneme translation) and a non-reading phonological composite were entered first in a regression analysis. In the last step, orthographic competence was entered to investigate whether it accounted for variance after phonological processing was partialed out.

After establishing the independent contribution of orthographic competence, variability in orthographic competence was further investigated by comparing two subgroups of poor readers. Both subgroups were equally poor in reading their native language (Dutch), but one subgroup performed significantly better in tests of orthographic competence. Similar to the study of van der Leij and Morfidi (2006), we focused on students in secondary education who were in the process of learning English as a second language. We used the orthographic composite as a selection criterion for the subgroups of dyslexic students. There were, however, important differences between the present study and the earlier study.

First, the students in the present investigation were on average a year older. Their greater experience with L2 English gave us the opportunity to determine whether the predictions of the PCVOD model are independent of reading experience. Second, in addition to replicating the phonological core deficit findings, the main focus of the present study was on tasks that involve orthographic competence. In addition to lexical decision tasks to tap orthographic knowledge, we included a flashed word identification task to measure orthographic competence skill. We reasoned that flashed presentation prevents the reader from using a graphemephoneme decoding strategy, forcing him or her to read larger (orthographic) units. As noted in an earlier section, according to the 'automatic decoding deficit' hypothesis of Yap and van der Leij (1993), dyslexics perform poorly in this respect, in general. Possibly, some of them are helped when their better orthographic competence skill is triggered by the need to process larger orthographic units. Third, a larger sample was used in order to increase statistical power. In addition, the range in age and in class and school level was smaller, resulting in a more homogeneous sample. Fourth, spelling was included.

By selecting students whose general learning ability is within the normal range, we controlled for the influence of general intellectual differences. In addition, differences in reading ability were established by using strict criteria for normal versus poor reading. Thus, according to traditional conventions (see for example Stanovich, 1988) our poor readers can be labeled dyslexics. We also controlled for reading experience with a questionnaire assessing the personal reading habits of the participants.

\section{Method}

\section{Participants}

The native language of the participants, Dutch (L1), is characterized by a relatively high syllabic complexity (determined by the abundance of closed syllables and 
consonant clusters) - comparable to English, German and the Scandinavian languages - and a relatively low orthographic complexity (determined by the degree of inconsistency in grapheme-phoneme correspondence) (Seymour et al., 2003). Consequently, the main difference between Dutch and English pertains to orthography (with English a deep 'outlier', and Dutch as relatively transparent) and not to syllabic complexity. In this sample, students learn their second language English (L2) when they enter secondary school at the age of twelve. The participants of our study had received about two lessons of $50 \mathrm{~min}$ a week in English from grade seven upwards. At the time of testing they were attending grade 10.

Ninety-four secondary school students from four high schools participated in this study. School counsellors nominated a total of 47 dyslexics and a group of 47 normal readers matched on age, gender and type of school. Since children with an IQ below 85 do not attend the schools participating in this study, we saw no need to test IQ. There were no children involved with other learning disabilities or neuropsychological deficits.

In order to verify the counsellors' classification, we used the Dutch One Minute Test (Brus \& Voeten, 1973), a test of word reading fluency, which is scored in words read correctly in one minute. The norms of Kuijpers et al. (2003) were used to verify the designation of the control and dyslexic students. We excluded students in the dyslexic group who scored above the 25th percentile and also students in the control group who scored below the 25th percentile. This left 72 participants; 37 dyslexic and 35 normal readers. There were 20 boys in each group, 17 girls in the dyslexic group and 15 girls in the control group. There was no relationship between the participants' reading status (dyslexic/control) and gender, $\chi^{2}(1, N=72)=.07$, $p=.79$. The mean age of the dyslexics was 187.2 months $(S D=9.54)$ compared to 187.9 months $(S D=8.97)$ for the controls. Furthermore the two groups did not differ on verbal ability $(F<1)$ and receptive vocabulary in either Dutch or English $(F<1)$. The characteristics of the dyslexics and the control group of normal readers are presented in Table 1.

Table 1 Characteristics of the participants on background and selection variables

\begin{tabular}{|c|c|c|c|c|c|c|}
\hline \multirow{2}{*}{$\begin{array}{l}\text { Variables (max) } \\
N\end{array}$} & \multicolumn{2}{|c|}{ Controls } & \multicolumn{2}{|c|}{ Dyslexics } & \multirow{2}{*}{$\begin{array}{l}\text { Manova } \\
F(1,69)\end{array}$} & \multirow{2}{*}{$\begin{array}{l}\text { Effect size } \\
\eta_{\mathrm{p}}^{2}\end{array}$} \\
\hline & 35 & & 37 & & & \\
\hline Boys & 20 & & 20 & & & \\
\hline \multirow[t]{2}{*}{ Girls } & 15 & & 17 & & & \\
\hline & $M$ & $S D$ & $M$ & $S D$ & & \\
\hline Mean age in months & 187.9 & 8.97 & 187.16 & 9.54 & $.11^{\mathrm{ns}}$ & .002 \\
\hline Word reading fluency L1 (116) & 98.2 & 8.72 & 68.81 & 10.58 & $164.13^{* *}$ & .70 \\
\hline Verbal competence (26) & 13.77 & 3.86 & 14.05 & 4.88 & $.07^{\mathrm{ns}}$ & .001 \\
\hline Receptive vocabulary Dutch (20) & 13.29 & 2.48 & 12.78 & 3.12 & $.57^{\mathrm{ns}}$ & .008 \\
\hline Receptive vocabulary English (20) & 16.31 & 2.58 & 16.43 & 2.02 & $.05^{\mathrm{ns}}$ & .001 \\
\hline Start learning English & 2.09 & .61 & 1.92 & 8.29 & $.93^{\text {ns }}$ & .013 \\
\hline
\end{tabular}

Note. $* * p<.01, \mathrm{~ns}=$ not significant 
Selection variables

\section{Word reading fluency, L1, Dutch}

The Een Minuut Test [One Minute Test] (Brus \& Voeten, 1973) was used to identify poor readers in L1, Dutch. The test consists of 116 words of increasing difficulty. The participant is asked to read aloud as many words as possible in one minute. The test score is the number of words read correctly in $60 \mathrm{~s}$. Parallel test and test-retest reliabilities are over .80 (Brus \& Voeten, 1973; van den Bos, lutje Spelberg, Scheepstra, \& de Vries, 1994).

\section{Control measures}

\section{Verbal ability}

Verbal competence was measured with the Similarities subtest of the Wechsler Adult Intelligence Scale (Wechsler, 1955, Dutch adaptation, 1970). The participants are asked in what way two words are similar. Each of the 13 questions is awarded 2, 1 , or 0 points. After four consecutive 0 -point answers, the test is discontinued. Splithalf reliability of .81 is reported.

\section{Receptive vocabulary $L 1$ and L2}

Following van der Leij and Morfidi (2006), we constructed two short versions of the Peabody Picture Vocabulary Test (Manschot \& Bonnema, 1978) to assess oral language competence. The English version of the van der Leij and Morfidi test consists of 60 items. From each series of 10 consecutive items, we chose two items to construct a 20-item test. The same procedure was used to obtain the 20 Dutch items. In each item, four pictures with different meanings are presented and the participant is required to point to the picture corresponding to the given word. For the original versions, split-half reliability was reported to be .88 and .72 for Dutch and English respectively (van der Leij \& Morfidi, 2006). The reliability (Cronbach's $\alpha$ ) of this shortened Dutch and English version was lower, .56 and .44 respectively, probably due to test length.

\section{Literacy (reading habits) questionnaire}

A questionnaire assessing background information regarding exposure to print and perceived skill in reading and writing in Dutch and English, and in understanding and speaking (English), both at school and in leisure time, was developed. The questionnaire also included items about the experience of the participants with the use of computers. The questionnaire consisted of 28 multiple-choice questions. A translation of the Dutch questionnaire is given in the Appendix. 
Phonological processing

\section{Phonemic awareness}

To measure phonemic awareness a computerized word reversal task was developed as part of the Interactive Dyslexia Test (IDT; Bekebrede, van der Leij, Plakas, \& Schijf, 2006). This subtest was originally developed by Buis (n.d.). Participants hear two pseudowords (e.g., git-tig) then press a true or false button on the computer keyboard to indicate whether the second word is the reverse of the first. The test consists of 10 examples and 60 test items-all monosyllabic words with one or two consonants at the beginning or end of the word. The internal consistency (Cronbach's $\alpha$ ) was found to be .78 .

\section{Phonemic awareness (spoonerisms)}

A second way to measure phonemic awareness is by using a spoonerisms task. Van der Leij and Morfidi (2006) adapted the original German version of Landerl, Wimmer, and Frith's spoonerisms task (1997). The students are required to transpose the onsets of two words. It consists of 15 pairs of two words. The first five items have a single initial consonant. In the following five items one word of the pair has a single initial consonant, and the other word is a consonant cluster. In the last five items both words have a consonant cluster. To reduce the verbal short-term memory load, pictures of the items were shown during each word pair. The internal consistency (Cronbach's $\alpha$ ) was found to be .78 (van der Leij \& Morfidi, 2006).

\section{Rapid serial naming}

The participants are required to read aloud a series of 50 digits $(8,1,3,6,5$ in random order) as quickly and accurately as possible, while the time is recorded (Denckla \& Rudel, 1974). Test-retest reliability of .74 has been reported (van der Leij \& Morfidi, 2006).

Orthographic competence

\section{Orthographic choice, L1, Dutch}

To measure orthographic knowledge in the participants' native tongue, Dutch, van der Leij and Morfidi (2006) developed an adaptation of the Olson, Forsberg, Wise, and Rack (1994) orthographic choice task in English. This was based on Assink and Kattenberg's (1994) six categories of spelling difficulty in Dutch (analogy, congruence, etymology, double vowels or consonants, pronunciation options and spelling of loan words). Forty pairs of homophonic words (e.g., 'blauw-blouw' [blue]) are presented on an A4-format page. The participants are asked to choose the 
correctly spelled word, and time was also recorded. The internal consistency (Cronbach's $\alpha$ ) was found to be 64 .

\section{Orthographic choice, L2, English}

This test (Olson et al., 1994) was used to evaluate orthographic knowledge in L2, English, and to identify dyslexics with differing degrees of orthographic knowledge. Forty pairs of words (e.g., wurd-word) are presented on an A4-format page. The participants are required to choose the correctly spelled word. Both accuracy and time are recorded. Internal consistency (Cronbach's $\alpha$ ) was found to be .78 .

\section{Flashed word identification}

In this test, a word appears on a computer screen for $200 \mathrm{~ms}$ and is then masked (IDT; Bekebrede et al., 2006). The participants are required to press a true or false button on the computer keyboard to indicate whether the word is correctly spelled or not. The test consists of three examples and four blocks of 10 items, with one, two and three syllables and loan words. Loan words are words from other languages that do not adhere to Dutch grapheme-phoneme correspondence conventions rules (e.g., 'milieu' [milieu], 'cyclus' [cycle]). In each block there are five correctly spelled words. When more than eight errors are committed in a single block, the test is discontinued. The reliability (Cronbach's $\alpha$ ) was found to be .66 .

Reading and spelling measures in Dutch

\section{Flashed word production, Dutch}

This task requires silent reading and spelling of real words and depends on both speed and accuracy. A word is flashed on a computer screen for $200 \mathrm{~ms}$ and then masked (IDT; Bekebrede et al., 2006). The participant is asked to type the flashed word. There are three examples followed by four blocks of 10 items with one, two and three syllables and loan words. The test is discontinued after eight incorrect responses in a single block. The internal consistency (Cronbach's $\alpha$ ) was found to be .88 .

\section{Flashed pseudoword production}

In this silent pseudoword reading and spelling task a pseudoword is flashed on a computer screen for $200 \mathrm{~ms}$ and then masked (IDT; Bekebrede et al., 2006). The participant is required to type the flashed pseudoword. The pseudowords were constructed by changing the vowels of the flashed word production test. The test consists of three examples followed by three blocks of 10 items containing one, two and three syllables. When the participant makes more than eight errors in a single 
block, the test is discontinued. The internal consistency (Cronbach's $\alpha$ ) was found to be .86 .

\section{Pseudoword reading fluency}

The Klepel (van den Bos et al., 1994) is a speeded reading test requiring phonological recoding. The test was constructed by changing consonants or vowels in the words in the Dutch One Minute Test without violating the pronunciation rules of Dutch. The Klepel consists of 116 pseudowords of increasing difficulty. The test score is the number of pseudowords correctly read in two minutes. Parallel test reliabilities are reported to be over .89 (van den Bos et al., 1994).

\section{Spelling to dictation (PI-dictee, [PI-dictation]), Dutch}

To test the spelling ability of the participants we used a shortened version of the Dutch PI-dictee test (Geelhoed, Bos, \& Kappers, 1994). This dictation test is a standardized spelling test containing nine blocks of items of increasing difficulty. We used the last block of this test, which has 15 polysyllabic words and added the Dutch word 'onmiddellijk' [immediately]. The words are read aloud and the participant is asked to write down the word correctly. The reliability (Cronbach's $\alpha$ ) of this shortened version was found to be .78 .

Reading and spelling measures in English

\section{Word reading fluency, L2, English (One Minute Test, OMT)}

The English One Minute Test (Fawcett \& Nicolson, 1996) demands speed and accuracy in reading English words. The test consists of 120 words of increasing difficulty. The test score is the number of words read correctly in one minute. Fawcett and Nicolson reported test-retest reliability of .99 .

\section{Flashed English word production}

In this silent reading and spelling task an English word is flashed on a computer screen for $200 \mathrm{~ms}$ and then masked (IDT; Bekebrede et al., 2006). The participants are asked to type the English word. Block one consists of 20 monosyllabic words, based on a wordlist developed by McDougall, Borowsky, MacKinnon, and Hymel (2005). Block 2 consists of 10 two-syllable words, block 3 consists of 10 threesyllable words and block 4 consists of 10 final 'e' words with one to three syllables. The test is discontinued after more than eight errors in a single block. Internal consistency (Cronbach's $\alpha$ ) was found to be .93 . 
The English words of the computerized test of van der Leij and Morfidi (2006) were used to construct a list of English pseudowords by changing the vowels of the words. The pseudoword-list consisted of 40 pseudowords with CVCC, CVCV, CVCVC and CVCCVC structures. The participants are required to read aloud the pseudowords as accurately as possible. The internal consistency (Cronbach's $\alpha$ ) of this test was found to be .83 .

\section{Procedure}

All tasks were individually administered in two sessions of up to $45 \mathrm{~min}$. One session included all the paper and pencil tests and the other the computerized tests. The paper and pencil tests were divided into separate Dutch and English subsets. Within each subset the order of the tests was randomized. For practical reasons, all participants received the same fixed order of the computerized tests; word reversal, flashed word identification, flashed word, pseudoword and English word production.

Analysis

Composite scores for phonological processing and orthographic competence were first created by summing the standardized scores for individual measures. Next, a regression analysis was conducted to investigate whether orthographic competence predicted variance in word recognition after variance accounted for by vocabulary and phonological processing is partialed out.

To test the predictions of the PCVOD model, the dyslexic group was divided in two, a group with low and a group with high orthographic competence.

The scores were submitted to a multivariate analysis of variance (MANOVA) with the different groups of measurements as dependent variables and group (control, $\mathrm{ORTH}^{+}$and $\mathrm{ORTH}^{-}$) as the between-subjects factor. Three planned contrasts examined differences between each group. If the multivariate statistics indicated significant overall differences ( $F$ values are presented in the tables), the statistics for the three pairwise contrasts were considered.

\section{Results}

\section{Descriptive statistics}

Table 2 presents the correlations of the phonological, orthographic and reading variables among all students $(N=72)$. Two out of three phonological variables revealed moderate correlations with word reading fluency (.62-.70). Only spoonerisms was an exception (.28). All orthographic variables showed moderate to higher correlations with word reading fluency (.63-.75). 
Table 2 Correlations of the phonological, orthographic and reading measures

\begin{tabular}{|c|c|c|c|c|c|c|c|c|c|c|c|}
\hline Variable & 1 & 2 & 3 & 4 & 5 & 6 & 7 & 8 & 9 & 10 & 11 \\
\hline 1. Fluency word reading & 1.00 & .86 & -.63 & 62 & 28 & .75 & .63 & .52 & .70 & .79 & .74 \\
\hline 2. Fluency pseudoword reading & & 1.00 & -.63 & .70 & .29 & 60 & 44 & .45 & .56 & .69 & .71 \\
\hline 3. Rapid serial naming & & & 1.00 & -.53 & -.21 & -.43 & -.30 & -.21 & -.33 & -.48 & -.37 \\
\hline 4. Word reversal & & & & 1.00 & .41 & .46 & .37 & .50 & .46 & .56 & .63 \\
\hline 5. Spoonerisms & & & & & 1.00 & .22 & .22 & .22 & .27 & .30 & .38 \\
\hline 6. Spelling & & & & & & 1.00 & .68 & .53 & .55 & .70 & .66 \\
\hline 7. Orthographic choice L1 & & & & & & & 1.00 & .63 & .45 & .57 & .54 \\
\hline 8. Orthographic choice L2 & & & & & & & & 1.00 & .54 & .68 & .59 \\
\hline 9. Flashed word identification & & & & & & & & & 1.00 & .69 & .65 \\
\hline 10. Flashed word production & & & & & & & & & & 1.00 & .75 \\
\hline $\begin{array}{l}\text { 11. Flashed pseudoword } \\
\text { production }\end{array}$ & & & & & & & & & & & 1.00 \\
\hline
\end{tabular}

Note. Correlations greater than .24 are significant at the .05 level

To investigate the relationships among the orthographic variables and phonological variables separately two principal component analyses were performed (see Tables 3 and 4 for the component loadings). Both analyses revealed only one component with an eigenvalue greater than one, respectively an orthographic and phonological component. Spoonerisms had the lowest loading of the phonological variables.

Because spoonerisms had a low correlation with both the other two phonological measures and with reading, as well as a low factor loading and a possible ceiling effect, it was not included in the phonological composite. Therefore, the phonological composite consisted of two measures, word reversal and rapid serial naming. Following Cunningham et al. (2001), pseudoword reading fluency (phonological recoding) is treated as a separate measure because it involves grapheme-phoneme decoding. Based on the correlations and factor loadings the orthographic composite consisted of three measures, Dutch and English orthographic choice, and flashed word identification.

Hierarchical regression analyses

Hierarchical regression analyses were employed to investigate whether orthography plays a significant role in predicting L1 word reading fluency. In these analyses

Table 3 Principal component loadings for all three orthographic variables

Note. Accounted for $64 \%$ of the variance

\begin{tabular}{ll}
\hline Variable & Factor loading \\
\hline Flashed word identification & .80 \\
Orthographic choice L1 & .83 \\
Orthographic choice L2 & .80 \\
\hline
\end{tabular}


Table 4 Principal component loadings for all three phonological variables

Note. Accounted for $59.5 \%$ of the variance
Variable

Word reversal

Rapid serial naming

Spoonerisms
Factor loading

.87

$-.77$

.66

vocabulary was entered first at step 1 to control for vocabulary as a cognitive aspect in predicting word fluency. Followed by pseudoword reading fluency and the phonological composite at step 2 and 3 to partial out the phonological processing variance. To determine whether orthographic competence made an independent contribution, the orthographic composite was entered at the last step. The overall model was significant $F(4,66)=76.25, p<.01$ (see Table 5). Pseudoword reading explained $69 \%$ of the variance. After pseudoword reading was partialed out, the phonological composite did not predict word reading, but the orthographic composite accounted for an additional $8 \%$ of the variance.

When separate hierarchical regression analyses were employed for the normal students and dyslexic students to check whether orthography and phonology played different roles in the two groups, some differences were seen. For the normal readers the overall model explained a significant $50 \%$ of the total variance $F(4$, $29)=7.21, p<.01$, with vocabulary accounting for $15 \%$ of the variance, pseudoword reading for $21 \%$, phonology for $8 \%$ and orthography for $6 \%$. For the dyslexic students the model explained $59 \%$ of the total variance, $F(4,31)=13.65$, $p<.01$, with vocabulary accounting for $3 \%$ of the variance, pseudoword reading for $38 \%$, phonology for $2.5 \%$ and orthography for $20 \%$. In explaining L1 word reading fluency the role of phonological recoding was greater among dyslexics $(\beta=.44, t=3.30, p<.01)$ than among normal readers $(\beta=.19, t=1.07, \mathrm{~ns})$. The role of orthographic competence was also somewhat greater among dyslexics $(\beta=.48, t=4.17, p<.01)$ compared to control students $(\beta=.31, t=1.89$, $p=.069)$.

Hierarchical regression analyses were also employed to investigate whether orthography plays a significant role in predicting L1 spelling ability. In these

Table 5 Variance ( $R^{2}$ change) in predicting Dutch (L1) word reading fluency explained by phonological and orthographic variables

\begin{tabular}{lllllll}
\hline Step & Variable & $R$ & $R^{2}$ change $(\%)$ & $F$ change & $\beta$ & $t$ \\
\hline 1 & Vocabulary L1 & .222 & 5 & $3.54^{\mathrm{ns}}$ & -.04 & $-.62^{\mathrm{ns}}$ \\
2 & Pseudoword reading fluency & .857 & 69 & $173.23^{* *}$ & .58 & $6.89^{* *}$ \\
3 & Phonological composite & .862 & .8 & $2.05^{\mathrm{ns}}$ & .10 & $1.26^{\mathrm{ns}}$ \\
4 & Orthographic composite & .908 & 8 & $30.145^{* *}$ & .37 & $5.49^{* *}$ \\
Total & & & 83 & & & \\
\hline
\end{tabular}

Note. Phonological composite $=$ word reversal and rapid serial naming; Orthographic composite $=$ orthographic choice L1, orthographic choice L2 and flashed word identification

$* * p<.01, \mathrm{~ns}=$ not significant 
analyses the same predictors were entered as in the prediction of word reading fluency. Vocabulary was entered first at step 1, followed by pseudoword reading fluency at step 2 and phonological and orthographic composites at steps 3 and 4 . A significant model again emerged, $F(4,66)=24.64, p<.01$, explaining $60 \%$ of the variance (see Table 6). Pseudoword reading fluency explained $36 \%$ of the variance. After pseudoword reading was partialed out phonological processing did not predict variance in spelling ability, whereas orthographic competence accounted for $23 \%$ of the variance. The influence of the orthographic composite $(\beta=.62, t=6.13$, $p<.01)$ was larger than phonological recoding $(\beta=.24, t=1.94, p=.057)$.

Overall it appears that in addition to phonological recoding, orthography plays an independent role in predicting L1 word reading fluency and spelling. At this age non-reading phonological processing does not contribute.

\section{Individual differences}

In this section the variability of orthographic competence among the dyslexic readers is investigated. To examine individual differences, the dyslexic sample was subdivided into two subgroups with low and superior orthographic competence by using the median of the orthographic composite as a cut-off point. The dyslexics with a score below the median $(n=18)$ formed the group with low orthographic competence $\left(\mathrm{ORTH}^{-}\right)$. The dyslexic readers with a score above the median $(n=19)$ formed the group with superior orthographic competence $\left(\mathrm{ORTH}^{+}\right)$. To verify this classification, the orthography measures were considered across the three groups. The means, standard deviations and main effects of group are presented in Table 7 .

The contrast between the $\mathrm{ORTH}^{-}$and control students showed a significant difference on the orthographic composite $F(1,67)=85.68, p<.01, \eta_{\mathrm{p}}^{2}=.56$. The planned contrast revealed significant differences. The $\mathrm{ORTH}^{-}$subgroup performed worse on orthographic choice in English $F(1,67)=40.37, p<.01, \eta_{\mathrm{p}}^{2}=.38$ and in Dutch $F(1,67)=54.40, p<.01, \eta_{\mathrm{p}}^{2}=.45$. They were also inferior on flashed word identification $F(1,67)=38.62, p<.01, \eta_{\mathrm{p}}^{2}=.37$.

Table 6 Variance $\left(R^{2}\right.$ change) in predicting Dutch (L1) spelling ability explained by phonological and orthographic variables

\begin{tabular}{lllllll}
\hline Step & Variable & $R$ & $R^{2}$ change $(\%)$ & $F$ change & $\beta$ & $t$ \\
\hline 1 & Vocabulary L1 & .05 & .2 & $.17^{\mathrm{ns}}$ & -.22 & $-2.65^{*}$ \\
2 & Pseudoword reading fluency & .606 & 36 & $38.57^{* *}$ & .24 & $1.94^{.057}$ \\
3 & Phonological composite & .611 & .6 & $.65^{\mathrm{ns}}$ & .06 & $.50^{\mathrm{ns}}$ \\
4 & Orthographic composite & .776 & 23 & $37.53^{* *}$ & .62 & $6.13^{* *}$ \\
Total & & & 60 & & &
\end{tabular}

Note. Phonological composite $=$ word reversal and rapid serial naming; Orthographic composite $=$ orthographic choice L1, orthographic choice L2 and flashed word identification

$* p<.05, * * p<.01, \mathrm{~ns}=$ not significant 
Table 7 Mean scores $(M)$, standard deviations $(S D)$ and main effects of group for the control students and two dyslexic subgroups, $\left(\mathrm{ORTH}^{+}=\right.$superior orthographic competence, $\mathrm{ORTH}^{-}=$inferior orthographic competence) on orthographic competence

\begin{tabular}{|c|c|c|c|c|c|c|c|c|}
\hline \multirow[t]{2}{*}{ Task (max) } & \multicolumn{2}{|l|}{ Control } & \multicolumn{2}{|c|}{$\mathrm{ORTH}^{+}$} & \multicolumn{2}{|l|}{$\mathrm{ORTH}^{-}$} & \multirow{2}{*}{$\begin{array}{l}\text { Manova } \\
F(2,67)\end{array}$} & \multirow{2}{*}{$\begin{array}{l}\text { Effect size } \\
\eta_{\mathrm{p}}^{2}\end{array}$} \\
\hline & $M$ & $S D$ & $M$ & $S D$ & $M$ & $S D$ & & \\
\hline Orthographic choice L1 (40) & 37.15 & 2.05 & 36.11 & 1.94 & 32.28 & 2.89 & $27.75 * *_{\mathrm{a}, \mathrm{c}}$ & .45 \\
\hline Orthographic choice L2 (40) & 37.74 & 2.42 & 37.28 & 1.74 & 32.28 & 4.44 & $21.76 * *_{\mathrm{a}, \mathrm{c}}$ & .39 \\
\hline Flashed word identification (40) & 29.74 & 3.84 & 26.72 & 3.06 & 23.11 & 3.83 & $19.57 * *_{\mathrm{a}, \mathrm{b}, \mathrm{c}}$ & .37 \\
\hline Orthographic composite (z-score) & 1.4670 & 1.77 & .3373 & .84 & -3.080 & 2.10 & $43.30 * *_{a, b, c}$ & .56 \\
\hline
\end{tabular}

Note. Orthographic composite $=$ orthographic choice L1, orthographic choice L2 and flashed word identification

Significant between-group differences are indicated by subscripts: ${ }_{\mathrm{a}}$ Controls- $\mathrm{ORTH}^{-}$; ${ }_{\mathrm{b}}$ Controls$\mathrm{ORTH}^{+} ;{ }_{\mathrm{c}} \mathrm{ORTH}^{+}-\mathrm{ORTH}^{-}$

$* * p<.01$

The $\mathrm{ORTH}^{+}$performed worse on the orthographic composite than the control students $F(1,67)=5.29, p<.05, \eta_{\mathrm{p}}^{2}=.07$. However, the $\mathrm{ORTH}^{+}$group performed significantly worse than the control students on only one out of three orthographic measures that made up the orthographic composite. The $\mathrm{ORTH}^{+}$ performed similarly to the control students on orthographic choice in English $(F<1)$ and on orthographic choice in Dutch $F(1,67)=2.46, n s$. However, they performed worse in flashed word identification $F(1,67)=7.99, p<.01, \eta_{\mathrm{p}}^{2}=.11$.

Because the selection of the two subgroups was based on the orthographic composite, it follows that there was a significant difference on the orthographic composite between $\mathrm{ORTH}^{+}$and $\mathrm{ORTH}^{-} F\left(1,67=37.01, p<.01, \eta_{\mathrm{p}}^{2}=.36\right.$. In addition, on each of the three tasks there were differences in English orthographic choice $F(1,67)=25.91, p<.01, \eta_{\mathrm{p}}^{2}=.28$, Dutch orthographic choice $F(1$, $67)=25.78, p<.01, \eta_{\mathrm{p}}^{2}=.28$ and on flashed word identification $F(1,67)=8.78$, $p<.01, \eta_{\mathrm{p}}^{2}=.12$.

The PCVOD model also predicts that the three groups should not differ on the control measures. The main effects of group confirmed that this was the case. The control students and the two dyslexic groups did not differ on verbal competence (WAIS Similarities $F(2,69)=1.29, n s$; receptive vocabulary in Dutch $F(2$, $69)=2.12, n s$ and English $F<1$ ).

\section{Phonological processing}

To test the assumption of a common phonological core among dyslexics, performance of the three groups on the phonological tasks is presented in Table 8 .

The contrast between the $\mathrm{ORTH}^{-}$and control students showed a significant difference on the phonological composite, $F(1,69)=20.32, p<.01, \eta^{2}=.23$. The contrast between the $\mathrm{ORTH}^{-}$and control students showed significant differences on both phonological tasks (word reversal, $F(1,69)=16.64, p<.01, \eta_{\mathrm{p}}^{2}=.19$; rapid serial naming $\left.F(1,69)=13.77, p<.01, \eta_{\mathrm{p}}^{2}=.17\right)$. The $\mathrm{ORTH}^{+}$also performed 
Table 8 Mean scores $(M)$, standard deviations $(S D)$ and main effects of group for the control students and two dyslexic subgroups, $\left(\mathrm{ORTH}^{+}=\right.$superior orthographic competence, $\mathrm{ORTH}^{-}=$inferior orthographic competence) on phonological processing

\begin{tabular}{|c|c|c|c|c|c|c|c|c|}
\hline \multirow[t]{2}{*}{ Task (max) } & \multicolumn{2}{|c|}{ Control } & \multicolumn{2}{|l|}{$\mathrm{ORTH}^{+}$} & \multicolumn{2}{|l|}{$\mathrm{ORTH}^{-}$} & \multirow{2}{*}{$\begin{array}{l}\text { Manova } \\
F(2,69)\end{array}$} & \multirow{2}{*}{$\begin{array}{l}\text { Effect size } \\
\eta_{\mathrm{p}}^{2}\end{array}$} \\
\hline & $M$ & $S D$ & $M$ & $S D$ & $M$ & $S D$ & & \\
\hline Word reversal (60) & 50.31 & 5.32 & 44.95 & 6.48 & 43.33 & 6.35 & $10.12 * *_{a, b}$ & .23 \\
\hline Rapid serial naming (seconds) & 16.83 & 2.85 & 21.58 & 4.44 & 20.72 & 4.00 & $13.16^{* *} *_{\mathrm{a}, \mathrm{b}}$ & .28 \\
\hline Phonological composite (z-score) & .9684 & 1.22 & -.9332 & 1.77 & -.9730 & 1.63 & $15.05 * *_{\mathrm{a}, \mathrm{b}}$ & .30 \\
\hline
\end{tabular}

Note. Phonological composite $=$ word reversal and rapid serial naming

Significant between-group differences are indicated by subscripts: ${ }_{a}$ Controls- $\mathrm{ORTH}^{-}$; ${ }_{\mathrm{b}}$ Controls$\mathrm{ORTH}^{+}$

$* * p<.01$

more poorly on the phonological composite than the control students, $F(1$, $69)=20.20, p<.01, \eta_{\mathrm{p}}^{2}=.23$. The planned contrast between $\mathrm{ORTH}^{+}$and the control students revealed the same pattern of outcomes as those obtained in $\mathrm{ORTH}^{-}$ (word reversal, $F(1,69)=10.19, p<.01, \eta_{\mathrm{p}}^{2}=.13$; rapid serial naming, $F(1$, 69) $\left.=21.23, p<.01, \eta_{\mathrm{p}}^{2}=.24\right)$.

There was no significant difference between the two dyslexic subgroups on the phonological composite $(F<1)$. Supporting the predictions of the PCVOD model, the planned contrast comparing the two dyslexic subgroups indicated no significant differences on phonemic awareness and rapid serial naming $(F<1)$ between the two dyslexic subgroups.

\section{Reading and spelling measures in Dutch and English}

Reading and spelling ability in Dutch and English were compared across the three groups. The means, standard deviations and main effects for group are presented in Table 9. Note that Dutch word reading fluency is the selection variable.

Compared to the control students, the $\mathrm{ORTH}^{-}$subgroup performed significantly worse on all the Dutch reading and spelling tasks, word reading fluency, $F(1$, $67)=148.20, p<.01, \eta_{\mathrm{p}}^{2}=.69$, pseudoword reading fluency, $F(1,67)=75.95$, $p<.01, \eta_{\mathrm{p}}^{2}=.54$, flashed word production, $F(1,67)=79.51, p<.01, \eta_{\mathrm{p}}^{2}=.55$, flashed pseudoword production, $F(1,67)=60.50, p<.01, \eta_{\mathrm{p}}^{2}=.48$ and spelling ability, $F(1,67)=46.36, p<.01, \eta_{\mathrm{p}}^{2}=.41$. Furthermore, the ORTH ${ }^{-}$group attained lower scores than controls on the English reading and spelling measures: word reading fluency $F(1,67)=50.47, p<.01, \eta_{\mathrm{p}}^{2}=.43$, flashed English word production $F(1,67)=87.88, p<.01, \eta_{\mathrm{p}}^{2}=.57$ and English pseudoword accuracy $F(1,67)=10.88, p<.01, \eta_{\mathrm{p}}^{2}=.14$.

The $\mathrm{ORTH}^{+}$subgroup also scored significantly below the control students on Dutch word and pseudoword reading (word reading fluency $F(1,67)=84.56$, $p<.01, \eta_{\mathrm{p}}^{2}=.56$, pseudoword reading fluency $F(1,67)=58.28, p<.01$, $\eta_{\mathrm{p}}^{2}=.47$ ) as well as on Dutch silent reading and spelling of words (flashed word 
Table 9 Mean scores $(M)$, standard deviations $(S D)$ and main effects of group for the control students and two dyslexic subgroups $\left(\mathrm{ORTH}^{+}=\right.$superior orthographic competence, $\mathrm{ORTH}^{-}=$inferior orthographic competence) on the Dutch and English reading and spelling measures

\begin{tabular}{|c|c|c|c|c|c|c|c|c|}
\hline \multirow[t]{2}{*}{ Task (max) } & \multicolumn{2}{|c|}{ Control } & \multicolumn{2}{|c|}{$\mathrm{ORTH}^{+}$} & \multicolumn{2}{|c|}{$\mathrm{ORTH}^{-}$} & \multirow{2}{*}{$\begin{array}{l}\text { Manova } \\
F(2,67)\end{array}$} & \multirow{2}{*}{$\begin{array}{l}\text { Effect } \\
\text { size } \\
\eta_{\mathrm{p}}^{2}\end{array}$} \\
\hline & $M$ & $S D$ & $M$ & $S D$ & $M$ & $S D$ & & \\
\hline \multicolumn{9}{|l|}{ Dutch } \\
\hline Word reading fluency L1 (116) & 98.00 & 8.77 & 72.8 & 7.83 & 64.1 & 12.09 & $88.57 * *_{\mathrm{a}, \mathrm{b}, \mathrm{c}}$ & .73 \\
\hline $\begin{array}{l}\text { Pseudoword reading fluency L1 } \\
\text { (116) }\end{array}$ & 96.00 & 11.99 & 62.83 & 18.23 & 57.41 & 16.34 & $50.33 * *_{\mathrm{a}, \mathrm{b}}$ & .60 \\
\hline Flashed word production (40) & 37.24 & 2.66 & 33.39 & 4.88 & 25.00 & 6.94 & $39.77 * *_{\mathrm{a}, \mathrm{b}, \mathrm{c}}$ & .55 \\
\hline $\begin{array}{l}\text { Flashed pseudoword production } \\
\text { (30) }\end{array}$ & 18.09 & 4.29 & 14.50 & 3.45 & 9.12 & 3.41 & $30.41 * *_{\mathrm{a}, \mathrm{b}, \mathrm{c}}$ & .48 \\
\hline Spelling ability (16) & 12.62 & 2.31 & 10.00 & 1.75 & 7.29 & 3.78 & $23.85^{* *} *_{\mathrm{a}, \mathrm{b}, \mathrm{c}}$ & .42 \\
\hline \multicolumn{9}{|l|}{ English } \\
\hline Word reading fluency L2 (120) & 74.32 & 14.98 & 51.39 & 12.74 & 45.29 & 12.05 & $31.42 * *_{\mathrm{a}, \mathrm{b}}$ & .49 \\
\hline $\begin{array}{l}\text { Pseudoword reading accuracy L2 } \\
\text { (40) }\end{array}$ & 36.85 & 3.29 & 34.11 & 4.86 & 32.88 & 4.51 & $6.26 * *_{a, b}$ & .16 \\
\hline Flashed word production (50) & 44.09 & 4.39 & 36.28 & 6.30 & 26.18 & 9.42 & $44.48 * *_{\mathrm{a}, \mathrm{b}, \mathrm{c}}$ & .57 \\
\hline
\end{tabular}

Note. Significant between-group differences are indicated by subscripts: ${ }_{\mathrm{a}}$ Controls- $\mathrm{ORTH}^{-} ;{ }_{\mathrm{b}} \mathrm{Con}-$ trols- $\mathrm{ORTH}_{+} ;{ }_{\mathrm{c}} \mathrm{ORTH}^{+}-\mathrm{ORTH}^{-}$

$* * p<.01$

production $F(1,67)=8.16, p<.01, \eta_{\mathrm{p}}^{2}=.11$ ) and pseudowords (flashed pseudoword production $\left.F(1,67)=10.05, p<.01, \eta_{\mathrm{p}}^{2}=.13\right)$ and spelling $F(1$, $67)=11.63, p<.01, \eta_{\mathrm{p}}^{2}=.15$. On English word reading fluency $F(1$, $67)=32.71, p<.01, \eta_{p}^{2}=.33$ they performed more poorly than the control readers, also at silent English reading and spelling (flashed English word production $\left.F(1,67)=17.35, p<.01, \eta_{\mathrm{p}}^{2}=.21\right)$ and English pseudoword accuracy $F(1$, $67)=5.39, p<.05, \eta_{\mathrm{p}}^{2}=.08$.

The $\mathrm{ORTH}^{+}$subgroup, however, performed significantly better than the $\mathrm{ORTH}^{-}$ subgroup in Dutch word reading fluency $F(1,67)=7.65, p<.01, \eta_{\mathrm{p}}^{2}=.10$. Both subgroups did not differ at pseudoword reading fluency $F(1,67)=1.16, n s$. The $\mathrm{ORTH}^{+}$group were also better in flashed word production $F(1,67)=28.83$, $p<.01, \eta_{\mathrm{p}}^{2}=.30$, in flashed pseudoword production $F(1,67)=16.80, p<.01$, $\eta_{\mathrm{p}}^{2}=.20$ and in spelling ability $F(1,67)=9.23, p<.01, \eta_{\mathrm{p}}^{2}=.12$. With regard to English, the $\mathrm{ORTH}^{+}$were superior in flashed word production $F(1,67)=21.56$, $p<.01, \eta_{\mathrm{p}}^{2}=.25$ but not in word reading fluency $(F<1)$ and English pseudoword accuracy $(F<1)$.

\section{Questionnaire}

Questions relating to print exposure, the amount of time spent reading and writing in English, watching English television revealed no significant group effects. The only 
questionnaire item that revealed a significant group effect concerned the amount of time spent learning English in school $F(2,68)=6.01, p<.01, \eta_{\mathrm{p}}^{2}=.15$; the normal group reported spending less time learning English, and there was a significant difference between the two dyslexic subgroups $F(1,68)=5.27, p<.05$, $\eta_{\mathrm{p}}^{2}=.07$ in which the $\mathrm{ORTH}^{-}$group reported spending more time in learning English than the $\mathrm{ORTH}^{+}$group. To control for print exposure in Dutch, we asked the participants about the amount of time they spent on reading and writing Dutch. These questions revealed no significant group differences.

Four questions relating to how the students perceived their skill in reading and learning English and Dutch revealed significant group effects in which the control students had the least difficulties in comparison with the two dyslexic subgroups. These questions were: "How easy do you find it to read English?" $F(2,69)=3.80$, $p<.05, \eta_{\mathrm{p}}^{2}=.10$; "How difficult do you find it to learn English?" $F(2$, $69)=7.24, p<.01, \eta_{\mathrm{p}}^{2}=.17$; "How many problems do you have with Dutch reading?" $F(2,69)=28.37, p<.001, \eta_{\mathrm{p}}^{2}=.45$; "How many problems do you have with Dutch spelling?" $F(2,69)=35.58, p<.001, \eta_{\mathrm{p}}^{2}=.49$. In the comparison of the two dyslexic subgroups the only significant difference emerging was on the question about problems with Dutch spelling, $F(1,69)=4.61, p<.05$, $\eta_{\mathrm{p}}^{2}=.06$, where the $\mathrm{ORTH}^{-}$group had more problems than the $\mathrm{ORTH}^{+}$group.

With regard to the number of times students felt they had to read an unknown English and Dutch word before attaining immediate recognition, significant group effects were found for English $F(2,69)=7.29, p<.01, \eta_{\mathrm{p}}^{2}=.18$ and Dutch $F(2$, $69)=4.99, p<.01, \eta_{p}^{2}=.13$. The control group recognized an unknown word quicker than both subgroups. The two subgroups were not significantly different $(F<1)$ on this measure either.

From the results of the questionnaire it appears that it is unlikely that the differences between $\mathrm{ORTH}^{+}$and $\mathrm{ORTH}^{-}$may be explained by differences in exposure to Dutch or English. This conclusion is supported by the fact that entering a composite of the questions regarding time spent on reading and writing in English and Dutch (questions 17, 18, 22 and 24, respectively, of the questionnaire, see Appendix) in the regression analysis did not change the overall picture. In predicting Dutch word reading fluency the overall model explained a significant $83 \%$ of the total variance $F(5,61)=57.73, p<.01$, with vocabulary accounting for $6 \%$ of the variance, composite exposure to Dutch and English accounting for 5\% (not significant), pseudoword reading for 62\%, phonology for $0.6 \%$ (not significant) and orthography for $9 \%$ of the variance. In predicting spelling ability the overall model explained a significant $60 \%$ of the total variance, with vocabulary accounting for $0.5 \%$ of the variance (not significant), composite exposure to Dutch and English accounting for $2.5 \%$ (not significant), pseudoword reading for $33 \%$, phonology for $0.5 \%$ (not significant) and orthography for $24 \%$ of the variance.

In addition, to investigate whether the finding that the $\mathrm{ORTH}^{-}$group reported spending more time on learning English than the other groups caused any different outcomes, this question was controlled for as a covariate. There appeared to be no different results in any of the English tasks. 


\section{Discussion}

In the present study, three major predictions of the PCVOD model of van der Leij and Morfidi (2006) were investigated: (a) phonological processing and orthographic competence contribute independently to the explanation of variance in reading and spelling, (b) all dyslexics suffer from a phonological core deficit, (c) within the group of dyslexics there exists larger variability in orthographic competence than in phonological processing.

The first prediction was supported by the findings of the present study. However, only phonological recoding-essentially a reading task-played an important role in the prediction, in contrast to phonemic awareness and rapid serial naming. In addition, the findings revealed that orthographic competence is an independent predictor of word reading fluency, and plays an even more important role in predicting spelling. The findings also supported the second and third predictions. The dyslexic readers were weak in all tasks measuring phonological processing but showed larger variation in orthographic competence and on reading and spelling measures that rely more on orthographic competence.

The results of the present study support the view that phonological recoding is the key process in reading and spelling performance (Share, 1995). At this age (on average, 15.5 years), phonemic awareness does not play a role in the predictions. This finding is not surprising because, as mentioned in the introduction, in relatively transparent orthographies the role of phonemic awareness is confined to the initial phase of learning to read (de Jong \& van der Leij, 1999; Wimmer et al., 2000). The finding that rapid serial naming does not contribute, in contrast to a related study (Morfidi et al., 2007), is related to the predictive power of the task for pseudoword reading fluency that was not used as a predictor in the study of Morfidi et al. An important finding is that orthographic competence contributes to the prediction. Because the native language under study was Dutch with its relatively shallow orthography, this finding may be considered as an indication that the role of orthographic competence in reading development should be taken seriously (as is recommended by Castles \& Nation, 2006), independent of orthographic complexity of the language under study.

This recommendation is also supported by the results with regard to the other predictions. Two subgroups of dyslexic readers were selected who possessed good $\left(\mathrm{ORTH}^{+}\right)$or poor orthographic competence $\left(\mathrm{ORTH}^{-}\right)$. The claim of the PCVOD model, that a universal core phonological deficit is the main feature of dyslexia, was confirmed by the equally poor performance of both subgroups on tasks that rely on phonological processing (i.e., phonemic awareness, rapid serial naming and phonological recoding in Dutch and English). (Below, we discuss the exception to this rule: flashed pseudoword production).

The second claim of the model, the variable orthographic differences, was supported by the fact that the $\mathrm{ORTH}^{+}$subgroup performed at the level of age-matched normal readers in L1 and L2 orthographic knowledge (both parts of the selection composite), confirming the findings of van der Leij and Morfidi (2006) and MillerGuron and Lundberg (2000). The validity of the differentiation based on orthographic competence is strengthened by the fact that $\mathrm{ORTH}^{+}$outperformed $\mathrm{ORTH}^{-}$when the 
tasks demanded speeded (pseudo) word processing and therefore involved some kind of processing of larger orthographic units. This finding was independent of word type (words or pseudowords), language (Dutch or English) or response mode (lexical decision or typing). Moreover, the advantage in orthographic knowledge in English and in Dutch could not be attributed to factors such as exposure to English or Dutch, phonological processing, verbal competence or vocabulary, indicating that it is a specific, individual characteristic.

Three aspects of the findings require comment: (1) the characteristics of the selected participants, in particular the subgroups, (2) the relevance of the findings to reading theory in a cross-linguistic perspective, and (3) the interpretation of the differences on speeded tasks between atypical readers in terms of early reading processes. In addition, some practical implications will be suggested. First, there is no reason to doubt whether all selected participants were dyslexic. Both subgroups performed at a normal level on non-reading tasks (Dutch verbal competence, and vocabulary in Dutch and English), but more poorly than the control group on all tasks that related to reading and spelling, with the exception of the $\mathrm{ORTH}^{+}$subgroup who were at normal levels in orthographic knowledge (L1 and L2). Although the $\mathrm{ORTH}^{+}$subgroup was better than the $\mathrm{ORTH}^{-}$ subgroup on measures that relate to orthographic competence, it is a subgroup with subnormal reading and spelling performance. It is therefore unlikely that the $\mathrm{ORTH}^{+}$subgroup may consist of relatively better readers with more reading experience, as is often found in subtype studies (Stanovich, Siegel, \& Gottardo, 1997). The subgroups were comparable in a variety of oral reading tasks: pseudoword reading fluency in L1, pseudoword accuracy in L2, and word reading fluency in L2. In addition, the subgroups did not differ on tasks that involve non-print phonological processing, indicating their comparability with regard to the phonological core deficit. So, the $\mathrm{ORTH}^{+}$subgroup was only better on a subset of tasks measuring reading and reading subskills. Furthermore, differences in experience between the subgroups were only found in time spent in learning English $\left(\mathrm{ORTH}^{-}\right.$spend more time) and in problems with Dutch spelling $\left(\mathrm{ORTH}^{-}\right.$had more problems). Because there were no differences with regard to reading, we suggest that these differences reflect the consequences of the differences in orthographic competence but not the cause. However, it should be mentioned that the questionnaire was a self-report multiple-choice questionnaire. Future research should consider including more direct measures of reading experience. In addition, instead of the shortened versions of the vocabulary tasks that had only moderate reliability coefficients, the original longer and more reliable versions should be used in future research.

Second, with regard to reading theory in a cross-linguistic perspective, as mentioned before, the role of orthographic competence in a relatively shallow orthography should not be underestimated. It has been suggested by Seymour and Duncan (2004) in their unitary/dual foundation model that in a shallow orthography, only a phonological route of simple recoding ability (small units) is used (the alphabetic process). In contrast, in a deep orthography two options are available: the logographic process, which is direct whole-word recognition, and the alphabetic process. However, our findings support the conclusion that even in a 
more transparent orthography than English there exists evidence for a logographic process. Orthographic competence (which presumably is closely related to processing at the level of whole words and large orthographic units) was found to be an independent predictor of reading and spelling, together with phonological recoding that relies more on the translation of grapheme-phoneme correspondences. The independent contribution to the prediction should, however, not be taken as evidence in support for a model with separate routes in a relatively transparent orthography such as Dutch. The correlation between word and pseudoword reading is very high, both in fluency tasks (.86), and in flashed production tasks (.75). As a consequence, the subgroups should not be regarded as different subtypes based on two independent core deficits related to a defective route, but should be interpreted as evidence that the basic (phonological) core deficit can be combined with a gradual difference in orthographic competence. ${ }^{1}$

Third, on all the L1 and L2 speeded (pseudo) word processing tasks that involve identification or production (typing) as a response, the group with better orthographic competence outperformed the group with inferior orthographic competence. Whereas the flashed word identification and production results may be interpreted as a sign of better orthographic knowledge at the lexical level, the most striking result is the difference in the fast identification and production of pseudowords. This task involves the rapid processing (presented only $200 \mathrm{~ms}$ and masked afterwards), and producing by typing of pseudowords that, by definition, do not have a representation in memory. ${ }^{2}$

In an earlier study, the large difference between dyslexics and various control groups on a similar flashed pseudoword task was interpreted by Yap and van der Leij (1993) as evidence for an 'automatic decoding deficit.' Why does the ORTH ${ }^{+}$ subgroup of the present study escape from that deficit? To interpret that finding, it should be mentioned that the flashed (and masked) presentation of words aims to measure the early and automatic components of word recognition, the key indication of orthographic learning, independently of other, slower and more strategic influences on reading (Castles \& Nation, 2006, referring to Booth, Perfetti, $\&$ MacWinney, 1999). It seems to be that the $\mathrm{ORTH}^{+}$subgroup has a better memory

\footnotetext{
${ }^{1}$ Following an interesting suggestion of an anonymous reviewer we divided the dyslexic subgroups in two extreme groups, by dividing the dyslexics into three equal groups based on the orthographic composite, and leaving the 'middle' group out. The same results were obtained as in using all the dyslexics, except there was no longer a difference between the $\mathrm{ORTH}^{++}$and the control students on flashed word identification and on the overall orthographic composite. And on the flashed word production task the $\mathrm{ORTH}^{++}$also performed similarly to the control students. When defined as a more extreme group the $\mathrm{ORTH}^{++}$is even more similar to the controls on orthography and benefits from it in flashed word production.

${ }^{2}$ In answer to a query by an anonymous reviewer, it should be noted that differences in short-term memory are not a likely explanation. On a visual attention span task (comparable to the task of Bosse et al., 2007; results not described in this paper) that requested the participants to memorize and reproduce in the right order series of flashed capital letters, the two subgroups both differed from the controls, but not from each other.
} 
for word-traces at the level of larger orthographic units when encouraged to use it by flashed presentation (and masking) and silent reading. They appear to apply this word-trace memory not only to familiar words but also spontaneously in reading pseudowords. Although mapping from sound to print puts a strong demand on phonological processing, they seem to be able to adapt their identification strategy by grasping larger orthographic units. However, this higher-order recognition skill is only triggered in conditions involving silent reading and when identifying pseudowords in speeded processing conditions. In these conditions there is a less than maximal load on phonological processing, possibly because there is no oral output. When oral reading in unspeeded conditions is involved, as is the case in pseudoword reading fluency in L1 and accuracy of pseudoword reading in L2, the subgroups do not differ. Because the orthographic measures (orthographic knowledge in L1 and L2; flashed word identification) also do not implicate oral responding, the picture emerging is that the dyslexic subgroups differ in the ability to perceive large orthographic units at the word and sublexical level, but only when conditions do not place a burden on phonological processing as in oral reading. The influence of stimulus and task conditions on the variability in (pseudo) word-trace memory is an interesting topic for further study.

As a final remark, our findings have implications for practice in classrooms and other instructional settings. Speeded word and pseudoword processing may not only be a useful way to differentiate individual reading profiles within the dyslexic population from a diagnostic point of view but also as a way to stimulate orthographic processing at the (sub) lexical level in instruction and remediation (see for example, Das-Smaal, Klapwijk, \& van der Leij, 1996; van den Bosch, van Bon, $\&$ Schreuder, 1995). Therefore it seems of importance to include silent reading measures and tasks that rely on higher-order word-recognition skills in instruction and remediation in classrooms and future studies. Also it is important in future research to investigate the role of reading comprehension with regard to orthographic competence. Does better orthographic competence contribute to better comprehension when reading?

In conclusion, the PCVOD model is supported by the findings of the present study. The dyslexics in this study appear to share core phonological deficits; yet can be differentiated on the basis of orthographic competence. These characteristics may transcend orthographies, and thus appear to be universal. Dyslexics with greater orthographic competence tend to be better at perceiving larger orthographic units irrespective of lexicality and language, provided conditions favor such processing. Future research should attempt to understand how this model applies to other samples of dyslexic children, of varying ages and languages.

Acknowledgements We would like to thank the participating students and schools for their time and effort and Jolien Brederveld, Ulrike Insam, Sanne Stikkel, Dorine van Meel en Odile van der Kooij for their help in collecting the data.

Open Access This article is distributed under the terms of the Creative Commons Attribution Noncommercial License which permits any noncommercial use, distribution, and reproduction in any medium, provided the original author(s) and source are credited. 


\section{Appendix}

\section{Questions relating computer use}

1. Do you use a computer?

$$
\begin{aligned}
& \square \text { Yes } \\
& \square \text { No }
\end{aligned}
$$

If not, you can go on to question 6 .

2. With how many fingers can you type?

3. Can you touch type?
๑ Yes
a No

4. How often do you work at a computer: At such times how many hours do you work at the computer on average?

\section{Average amount of hours:}

๑ Every day

Several times per week

a Once a week

Less than once a week ...hours per day

....hours per week

....hours per week

5. Do you work at the computer only for school or also for your leisure?

․ Only for school

Only for leisure

- Both for school and for leisure

\section{Questions relating to the English language}

6. How easy do you find reading English?

․ Very easy

․ Easy

․ Nor easy nor difficult

Not easy

口 Not easy at all 


\section{Appendix continued}

7. After how many times do you recognize an unknown English word immediately?
- After one time
- After several times
口 After many times
Never

8. How easy do you find speaking English?
․ Very easy
ㅁ Easy
Nor easy nor difficult
- Not easy
․ Not easy at all

9. When did you start learning English?

Before grade 5 (primary school)

a Grade 5 (primary school)

․ Grade 6 (primary school)

Grade 7 (secondary school)

․ Grade 8 (secondary school)

10. Do you find it difficult learning English?
- Not difficult at all
․ Not difficult
․ Nor difficult nor easy
ㅁ Difficult

๑ Very difficult

11. How much time do you spend on learning English?

Average amount of hours:
- Every day
- Several days a week
a Once a week
ㄴ. Less than once a week

...hours per day

...hours per week

...hours per week 


\section{Appendix continued}

12. How easy do you find it to understand English?
․ Very easy
ㅁ Easy
Nor easy nor difficult
․ Not easy
․ Not easy at all

13. How many hours of English television programs do you watch on average?

a Less than one hour a week

- 1 to 3 hours a week

a 3 to 6 hours a week

๑ 7 to 10 hours a week

a More than 10 hours a week

14. How many hours of English television programs without subtitles do you watch on average (i.e., BBC/CNN)?

๑ Less than one hour a week

- 1 to 3 hours a week

- 3 to 6 hours a week

व 7 to 10 hours a week

口 More than 10 hours a week

15. Do you have problems reading the subtitles on television?
- Yes
№

16. How often do you listen to English spoken music on average?
- Every day
口 Several times a week
- Once a week
․ Less than once a week

17. On average how many hours a week do you spend on reading English (books, magazines, newspapers, internet)?

\section{For school}

๑ Less than 1 hour a week

a 1 to 3 hours a week

๑ 3 to 6 hours a week

๑ 7 to 10 hours a week

a More than 10 hours a week

\section{For leisure}

a Less than 1 hour a week

a 1 to 3 hours a week

3 to 6 hours a week

- 7 to 10 hours a week

a More than 10 hours a week 


\section{Appendix continued}

18. On average how many hours a week do you spend on writing in English (email, letters, diary etc.)?

\section{For school}

- Less than 1 hour a week

口 1 to 3 hours a week

- 3 to 6 hours a week

- 7 to 10 hours a week

- More than 10 hours a week

\section{For leisure}

a Less than 1 hour a week

๖ 1 to 3 hours a week

- 3 to 6 hours a week

a 7 to 10 hours a week

a More than 10 hours a week

19. What was your latest mark for English?

\section{Questions relating Dutch:}

20. Do you have problems with reading in Dutch?
- No problems
- A little
a Frequently
a Many
a Very much

21. After how many times do you recognize an unknown Dutch word immediately?
๑ After one time
a After several times
๑ After many times
๖ Never

22. On average how many hours a week do you spend on Dutch reading (books, magazines, papers, internet)?

\section{For school}

๑ Less than 1 hour a week

a 1 to 3 hours a week

- 3 to 6 hours a week

๖ 7 to 10 hours a week

a More than 10 hours a week

\section{For leisure}

a Less than 1 hour a week

- 1 to 3 hours a week

- 3 to 6 hours a week

a 7 to 10 hours a week

a More than 10 hours a week

23. Do you have problems with spelling?

- No problems

口 A little 


\section{Appendix continued}
๑ Frequent
a Many
๑ Very much

24. On average how many hours a week do you spend on writing Dutch (e-mail, letters, diary etc.)?
For school
- Less than 1 hour a week
- 1 to 3 hours a week
व 3 to 6 hours a week
- 7 to 10 hours a week
a More than 10 hours a week

For leisure

a Less than 1 hour a week

- 1 to 3 hours a week

व 3 to 6 hours a week

- 7 to 10 hours a week

\ More than 10 hours a week

25. Are you better in reading English or Dutch?
- English
a Dutch
๑ Equally well

26. What was your latest mark for Dutch?

27. Are you left or right handed?
口 Left handed
口 Right handed

28. Do you know if other family members have/had problems with reading and/or spelling? If yes, who?

\section{References}

Assink, E. M. H., \& Kattenberg, G. (1994). Higher-order linguistic influences on development of orthographic knowledge: Illustrations from spelling problems in Dutch and assessment tools. In V. W. Berninger (Ed.), The varieties of orthographic knowledge. Vol. 1. Theoretical and developmental issues (pp. 111-136). Dordrecht: Kluwer Academic Publisher.

Badian, N. A. (2001). Phonological and orthographic processing: Their roles in reading prediction. Annals of Dyslexia, 51, 179-202.

Bailey, C. E., Manis, F. R., Pedersen, W. C., \& Seidenberg, M. S. (2004). Variation among developmental dyslexics: Evidence from a printed-word-learning task. Journal of Experimental Child Psychology, $87,125-154$.

Beaton, A. A. (2004). Dyslexia, reading and the brain. Hove: Psychology Press.

Bekebrede, J. I., van der Leij, A., Plakas, A., \& Schijf, T. (2006). Interactieve Dyslexie Test [Interactive Dyslexia Test]. Experimental Version.

Booth, J. R., Perfetti, C. A., \& MacWinney, B. (1999). Quick, automatic, and general activation of orthographic and phonological representations in young readers. Developmental Psychology, 35, $3-19$. 
Bosman, A. M. T., \& van Orden, G. C. (1997). Why spelling is more difficult than reading. In C. A. Perfetti, L. Rieben, \& M. Fayol (Eds.), Learning to spell: Research, theory, and practice across languages (pp. 173-194). Hillsdale, NJ: Erlbaum.

Bosse, M., Tainturier, M. J., \& Valdois, S. (2007). Developmental dyslexia: The visual attention span deficit hypothesis. Cognition, 104, 198-230.

Bowey, J. A. (2005). Predicting individual differences in learning to read. In M. J. Snowling \& C. Hulme (Eds.), The science of reading: A handbook (pp. 155-172). Malden, MA: Blackwell Publishing.

Bowey, J. A., \& Miller, R. (2007). Correlates of orthographic learning in third-grade children's silent reading. Journal of Research in Reading, 30, 115-128.

Bowey, J. A., \& Muller, D. (2005). Phonological recoding and rapid orthographic learning in thirdgraders' silent reading: A critical test of the self-teaching hypothesis. Journal of Experimental Child Psychology, 92, 203-219.

Brus, B. T., \& Voeten, M. J. (1973). Een-minuut-test [One-minute-test]. Nijmegen: Berkhout.

Buis, P. (n.d.). Woordomkeringen test [Word reversal test].

Burt, J. S. (2006). What is orthographic processing skill and how does it relate to word identification in reading? Journal of Research in Reading, 29, 400-417.

Caravolas, M., Volín, J., \& Hulme, C. (2005). Phoneme awareness is a key component of alphabetic literacy skills in consistent and inconsistent orthographies: Evidence from Czech and English children. Journal of Experimental Child Psychology, 92, 107-139.

Cardoso-Martins, C., \& Pennington, B. (2004). The relationship between phoneme awareness and rapid serial naming skills and literacy acquisition: The role of developmental period and reading ability. Scientific Studies of Reading, 8, 28-52.

Castles, A., \& Coltheart, M. (1993). Varieties of developmental dyslexia. Cognition, 47, 149-180.

Castles, A., \& Nation, K. (2006). How does orthographic learning happen? In S. Andrews (Ed.), From inkmarks to ideas: Challenges and controversies about word recognition and reading (pp. 151179). Hove: Psychology Press.

Comeau, L., Cormier, P., Grandmaison, E., \& Lacroix, D. (1999). A longitudinal study of phonological processing skills in children learning to read in a second language. Journal of Educational Psychology, 9, 29-43.

Cunningham, A. E. (2006). Accounting for children's orthographic learning while reading text: Do children self-teach? Journal of Experimental Child Psychology, 95, 56-77.

Cunningham, A. E., Perry, K. P., \& Stanovich, K. E. (2001). Converging evidence for the concept of orthographic processing. Reading and Writing: An Interdisciplinary Journal, 14, 549-568.

Cunningham, A. E., Perry, K. P., Stanovich, K. E., \& Share, D. L. (2002). Orthographic learning during reading: Examining the role of self-teaching. Journal of Experimental Child Psychology, 82, 185199.

Cunningham, A. E., \& Stanovich, K. E. (1990). Assessing print exposure and orthographic processing skill in children: A quick measure of reading experience. Journal of Educational Psychology, 82, 733-740.

Das-Smaal, E. A., Klapwijk, M. J. G., \& van der Leij, A. (1996). Training of perceptual unit processing in children with a reading disability. Cognition and Instruction, 14, 221-250.

de Jong, P. F., \& Share, D. L. (2007). Orthographic learning during oral and silent reading. Scientific Studies of Reading, 11, 55-71.

de Jong, P. F., \& van der Leij, A. (1999). Specific contributions of phonological abilities to early reading acquisition: Results from a Dutch latent variable longitudinal study. Journal of Educational Psychology, 91, 450-476.

de Jong, P. F., \& van der Leij, A. (2003). Developmental changes in the manifestation of a phonological deficit in dyslexic children learning to read a regular orthography. Journal of Educational Psychology, 95, 22-40.

Denckla, M. B., \& Rudel, R. G. (1974). Rapid “Automatized” Naming of pictured objects, colors, letters and numbers by normal children. Cortex, 10, 186-202.

Durgunoğlu, A. Y., Nagy, W. E., \& Hancin-Bhatt, B. J. (1993). Cross-language transfer of phonological awareness. Journal of Educational Psychology, 85, 453-465.

Ehri, L. C., Nunes, S. R., Stahl, S. A., \& Willows, D. M. (2001). Systematic phonics instruction helps students learn to read: Evidence from the National Reading Panel's meta-analysis. Review of Educational Research, 71, 393-447.

Fawcett, A. J., \& Nicolson, R. I. (1996). The dyslexia screening test. London: The Psychological Corporation. 
Fletcher-Flinn, C. M., Shankweiler, D., \& Frost, S. J. (2004). Coordination of reading and spelling in early literacy development: An examination of the discrepancy hypothesis. Reading and Writing: An Interdisciplinary Journal, 17, 617-644.

Gallagher, A. M., Laxon, V., Armstrong, E., \& Frith, U. (1996). Phonological difficulties in highfunctioning dyslexics. Reading and Writing: An Interdisciplinary Journal, 8, 499-509.

Geelhoed, J. W., Bos, W. N., \& Kappers, E. J. (1994). Handleiding PI-dictee [Manual PI-dictation]. Amsterdam/Duivendrecht: Paedologisch Instituut.

Geva, E., \& Siegel, L. S. (2000). Orthographic and cognitive factors in the concurrent development of basic reading skills in two languages. Reading and Writing: An Interdisciplinary Journal, 12, 1-30.

Gottardo, A., Yan, B., Siegel, L. S., \& Wade-Woolley, L. (2001). Factors related to English reading performance in children with Chinese as a first language: More evidence of cross-language transfer of phonological processing. Journal of Educational Psychology, 93, 530-542.

Ho, C. S.-H., \& Lai, D. N. (1999). Naming speed deficits and phonological memory deficits in Chinese developmental dyslexia. Learning and Individual Differences, 11, 173-186.

Ho, C. S.-H., Chan, D. W.-O., Lee, S.-H., Tsang, S.-M., \& Luan, H. V. (2004). Cognitive profiling and preliminary subtyping in Chinese developmental dyslexia. Cognition, 91, 43-75.

Jorm, A. F., \& Share, D. L. (1983). Phonological recoding and reading acquisition. Applied Psycholinguistics, 4, 103-147.

Joshi, M. R., \& Aaron, P. G. (2005). Handbook of orthography and literacy. Mahwah, NJ: Lawrence Erlbaum Associates.

Kuijpers, C., van der Leij, A., Been, P., van Leeuwen, T., ter Keurs, M., Schreuder, R., et al. (2003). Leesproblemen in het voorgezet onderwijs en de volwassenheid [Reading problems in secondary school and adulthood]. Pedagogische Studiën, 80, 272-287.

Kyte, C. S., \& Johnson, C. J. (2006). The role of phonological recoding in orthographic learning. Journal of Experimental Child Psychology, 93, 166-185.

Landerl, K., \& Wimmer, H. (2000). Deficits in phoneme segmentation are not the core problem of dyslexia: Evidence from German and English children. Applied Psycholinguistics, 21, $243-262$.

Landerl, K., Wimmer, H., \& Frith, U. (1997). The impact of orthographic consistency on dyslexia: A German-English comparison. Cognition, 63, 315-334.

Lindsey, K. A., Manis, F. R., \& Bailey, C. E. (2003). Prediction of first-grade reading in Spanish-speaking English-language learners. Journal of Educational Psychology, 95, 482-494.

Manschot, W., \& Bonnema, J. T. (1978). Handleiding bij de experimentele Nederlandse normering van de Peabody Picture Vocabulary Test [Manual of the experimental Dutch norms of the Peabody Picture Vocabulary Test]. Lisse: Swets \& Zeitlinger.

McDougall, P., Borowsky, R., MacKinnon, G. E., \& Hymel, S. (2005). Process dissociation of sight vocabulary and phonetic decoding in reading: A new perspective on surface and phonological dyslexias. Brain and Language, 92, 185-203.

Miller-Guron, L., \& Lundberg, I. (2000). Dyslexia and second language reading: A second bite at the apple? Reading and Writing: An Interdisciplinary Journal, 12, 41-61.

Morfidi, E., van der Leij, A., de Jong, P. F., Scheltinga, F., \& Bekebrede, J. (2007). Reading in two orthographies: A cross-linguistic study of Dutch average and poor readers who learn English as a second language. Reading and Writing: An Interdisciplinary Journal, 20, 753-784.

Nation, K., Angell, P., \& Castles, A. (2007). Orthographic learning via self-teaching in children learning to read English: Effects of exposure, durability, and context. Journal of Experimental Child Psychology, 96, 71-84.

Olson, R. K., Forsberg, H., Wise, B., \& Rack, J. P. (1994). Measurement of word recognition, orthographic, and phonological skills. In G. R. Lyon (Ed.), Frames of reference for the assessment of learning disabilities (pp. 243-277). Baltimore, MD: Brookes Publishing Co.

Rack, J. P., Snowling, M. J., \& Olson, R. K. (1992). The nonword reading deficit in developmental dyslexia: A review. Reading Research Quarterly, 27, 28-53.

Schwartz, M., Leikin, M., \& Share, D. L. (2005). Bi-literate bilingualism versus mono-literate bilingualism: A longitudinal study of reading acquisition in Hebrew (L2) among Russian-speaking (L1) children. Written Language \& Literacy, 8, 179-206.

Seymour, P. H. K., Aro, M., \& Erskine, J. M. (2003). Foundation literacy acquisition in European orthographies. British Journal of Psychology, 94, 143-174.

Seymour, P. H. K., \& Duncan, L. G. (2004, March). Reading acquisition and dyslexia in the European orthographies. Paper presented at the Sixth British Dyslexia Association International Conference, Warwick, UK. 
Shankweiler, D., \& Fowler, A. E. (2004). Questions people ask about the role of phonological processes in learning to read. Reading and Writing: An Interdisciplinary Journal, 17, 483-515.

Share, D. L. (1995). Phonological recoding and self-teaching: Sine qua non of reading acquisition. Cognition, 55, 151-218.

Share, D. L. (1999). Phonological recoding and orthographic learning: A direct test of the self teaching hypothesis. Journal of Experimental Child Psychology, 72, 95-129.

Share, D. L. (2004). Orthographic learning at a glance: On the time course and developmental onset of self-teaching. Journal of Experimental Child Psychology, 87, 267-298.

Share, D. L., \& Stanovich, K. E. (1995). Cognitive processes in early reading development: Accomodating individual differences into a model of acquisition. Issues in Education, 1, 1-57.

Stanovich, K. E. (1988). Explaining the differences between the dyslexic and the garden-variety poor readers: The phonological-core variable-difference model. Journal of Learning Disabilities, 21, 590-604.

Stanovich, K. E., \& Siegel, L. S. (1994). The phenotypic performance profile of reading-disabled children: A regression-based test of the phonological-core variable-difference model. Journal of Educational Psychology, 86, 24-53.

Stanovich, K. E., Siegel, L. S., \& Gottardo, A. (1997). Converging evidence for phonological and surface subtypes of reading disability. Journal of Educational Psychology, 89, 114-127.

Stanovich, K. E., \& West, R. F. (1989). Exposure to print and orthographic processing. Reading Research Quarterly, 24, 407-427.

van den Bos, K. P., lutje Spelberg, H. C., Scheepstra, A. J. M., \& de Vries, J. (1994). De Klepel. Vorm A en B. Een test voor de leesvaardigheid van pseudowoorden. Verantwoording, handleiding, diagnostiek en behandeling. [The Klepel. Form A and B. A test of reading pseudowords]. Nijmegen: Berkhout.

van den Bosch, K., van Bon, W. H. J., \& Schreuder, R. (1995). Poor readers' decoding skills: Effects of training with limited exposure duration. Reading Research Quarterly, 30, 110-125.

van der Leij, A., \& van Daal, V. H. P. (1999). Automatization aspects of dyslexia: Speed limitations in word identification, sensitivity to increasing task demands, and orthographic comprehension. Journal of Learning Disabilities, 32, 417-428.

van der Leij, A., \& Morfidi, E. (2006). Core deficits and variable differences in Dutch poor readers learning English. Journal of Learning Disabilities, 39, 74-90.

Vellutino, F. R., Fletcher, J. M., Snowling, M. J., \& Scanlon, D. M. (2004). Specific reading disability (dyslexia): What have we learned in the past four decades. Journal of Child Psychology and Psychiatry 45, 2-40.

Wagner, R. K., \& Torgesen, J. K. (1987). The nature of phonological processing and its causal role in the acquisition of reading skills. Psychological Bulletin, 101, 192-212.

Wechsler, D. (1955). Wechsler Adult Intelligence Scale. New York: Psychological Corporation. Dutchadaptation WAIS 1970. Lisse: Swets \& Zeitlinger.

Wimmer, H., \& Mayringer, H. (2002). Dysfluent reading in the absence of spelling difficulties: A specific disability in regular orthographies. Journal of Educational Psychology, 94, 272-277.

Wimmer, H., Mayringer, H., \& Landerl, K. (2000). The double-deficit hypothesis and difficulties in learning to read a regular orthography. Journal of Educational Psychology, 92, 668-680.

Wolf, M., Bally, H., \& Morris, R. (1986). Towards a more universal understanding of the developmental dyslexias: The contribution of orthographic factors. In V. W. Berninger (Ed.), The varieties of orthographic knowledge I: Theoretical and developmental issues. Dordrecht: Kluwer.

Wolf, M., \& Bowers, P. G. (1999). The double-deficit hypothesis for the developmental dyslexias. Journal of Educational Psychology, 91, 415-438.

Yap, R., \& van der Leij, A. (1993). Word processing in dyslexics: An automatic decoding deficit? Reading and Writing: An Interdisciplinary Journal, 5, 261-279.

Ziegler, J. C., \& Goswami, U. (2005). Reading acquisition, developmental dyslexia, and skilled reading across languages: A psycholinguistic grain size theory. Psychological Bulletin, 131, 3-29.

Ziegler, J. C., Stone, G. O., \& Jacobs, A. M. (1997). What is the pronunciation for -ough and the spelling for $/ \mathrm{u} /$ ? A database for computing feedforward and feedback consistency in English. Behavior Research Methods, Instruments, \& Computers, 29, 600-618. 